\title{
EDITORIAL
}

\section{POTENCIAL BIOTECNOLÓGICO DE LOS MICROORGANISMOS EXTREMÓFILOS}

En el mundo globalizado, se ha incrementado la demanda de nuevos productos y procesos tecnológicos; y existe una gran tendencia en el mercado de usar fuentes de carbono menos contaminantes para obtener energía y productos de interés industrial; lo que abre gran expectativa y futuro para la biotecnología blanca, la cual se basa en la producción de sustancias químicas utilizando microorganismos o productos de ellos.

En los años venideros, los nuevos productos biotecnológicos permitirán el desarrollo de las economías de los países, conservaran el medio ambiente, así como mejoraran la calidad de vida. Esta visión, se sustenta en que las técnicas industriales basadas en la biotecnología consumirán menos recursos energéticos, producirán menos residuos químicos, colaborarán con el medio ambiente al reducir las emisiones de gases causantes del efecto invernadero, proporcionarán sustitutos biológicos para procesos químicos perjudiciales y facilitarán el uso de energías alternativas y renovables.

En el planeta, existe una gran diversidad de microorganismos que producen metabolitos o realizan procesos que brindan oportunidades en diferentes campos biotecnológicos, los cuales tendrán gran impacto en la industria del futuro, y que es necesario considerar en los programas científico-tecnológicos estratégicos para el desarrollo de los países.

El aislamiento de nuevos microorganismos de ambientes extremos y su caracterización fisiológica, genética y metabólica permitirán el diseño de nuevas tecnologías y productos de aplicación en las industrias alimentaría, farmacéutica, cosmética, química, petroquímica, etc. En este contexto, los ambientes extremos como los salares, volcanes, aguas termales, glaciares, etc., contienen diversos microorganismos adaptados a condiciones extremas de salinidad, $\mathrm{pH}$ y temperatura.

Algunos de los metabolitos de los microorganismos extremofilos que podemos destacar son: la bacteriorrodopsina, que es una proteína retinal con gran futuro en aplicaciones muy diversas como en la elaboración de memorias ópticas, almacenamiento y procesado de información, holografía, moduladores espaciales de luz, etc. Los solutos orgánicos compatibles utilizados como agentes protectores y estabilizadores de biomoléculas y células, etc. Los biopolímeros como los exopolisacaridos, son usados como espesantes, emulgentes y gelificantes industriales; y los polihidroxialcanoatos son utilizados en la fabricación de plásticos biodegrdables, etc. Los carotenoides como el B-caroteno, la cantaxantina y la astaxantina son de gran utilidad en la formulación de alimentos, productos cosméticos y farmacéuticos. Algunas de estas aplicaciones han encontrado utilidad inmediata, mientras que otras son consideradas estratégicas para la prospectiva biotecnológica.

A partir de 2001, en la Facultad de Farmacia y Bioquímica de la Universidad Nacional Mayor de San Marcos, se viene estudiando la biodiversidad de microorganismos aislados en diferentes salinas del Perú, con el fin de contar con nuevas especies, cepas y productos, los cuales adecuadamente utilizados serán recursos nativos de gran impacto para el desarrollo biotecnológico sustentable del Perú. 